\section{Military Technical College}

Kobry El-Kobbah,

Cairo, Egypt

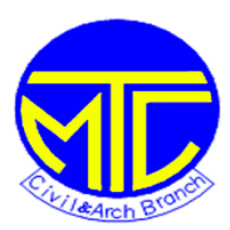

$11^{\text {th }}$ International Conference on Civil and Architecture

Engineering

ICCAE-11-2016

\title{
Development of Software Application for Digital Photogrammetric Systems (ADPS): Basic Level
}

\author{
Dr. A. Serwa \\ Faculty of Engineering in Mataria- HellwanUniversity-Egypt \\ BSc. MSc. PhD. MCP. MCSD. \\ GM of AUTOMATICA. \\ Dr.A.Serwa@m-eng.helwan.edu.eg \\ $+201003808123$
}

\begin{abstract}
AUTOMATICA is a software development teamwork its aim is researching, testing, integrating and validating of the complex computations used for Civil Engineering. The need of having researching software package in the field of photogrammetry is greatly increased. A lot of photogrammetric tasks can be considered enigmatic in details so as to prevent creative researchers to apply their ideas. Application for DigitalPhotogrammetric Systems (ADPS) applies many of photogrammetric models, algorithms and meets standards for computation, simulating and modeling in Photogrammetry. All coding is performed using VB Integrated Development Environment (IDE). ADPS is extensive software that ranges from basic (Current version) to advanced operations (future versions).
\end{abstract}

Key words:Digital Photogrammetry, Aerial, Terrestrial, Software Development, Visual Basic.

\section{1- Introduction:}

Digital photogrammetry advances rapidlydue to the advance of new cameras technology, new software, newalgorithms for data extraction and processing. The process of data 
acquisition and processing interrestrial photogrammetry are different from aerial photogrammetry so that the software packages inboth are different. In aerial photogrammetric software is dedicated mainly to cartography and often not focusingon modeling. Also the treatment of image coordinates is concerned with metric cameras.On the other hand, terrestrial photogrammetry is mainly concerned with documentationand modeling. In addition it handles both non-metric and metric cameras. The main features ofsome commercial and education software packages are given in this research. ADPS software package in its basic stage is introduced as educational and research product. The advantage of researcher-made software is to convert the researchers from follow to creation. Also one can make his own bias in this software as the problem definer, system analyzer, system designer, system developer and system tester is the same person (in the case of ADPS).

\section{2- Review:}

One must develop his own simulator applications to imagine the research problem that cannot be found in the commercial Software (SW) [Sedek and Serwa, 2016]. The creative tools offered by modern digital systems are being exploited in education and research. This is clear in the field of geomatics (particularly photogrammetry and remote sensing). Indeed, various tutorials or interactive e-learning environments are now available on the Web [Fluehler et al., 2005]. Until the 2000 year, the photogrammetric and computer vision community have worked almost independently on the problem of 3D reconstruction out of stereo image acquisition [Forstner, 2009]. The photogrammists were working on well calibrated analogical (eventually scanned) images for metrological applications, using bundle adjustment in Euclidean space, in process involving a lot of human interaction [Kasser 2002]. Usually the term 'educational photogrammetric SW'refers mainly to simple photogrammetric tools which are intended to limit the need for interference by experts. This is the case of 'ADPS'.Educational SW in the field of photogrammetry meets demonstration tools like the 'Digital Monoplotting Teaching Program', which is mainly addressed to the teaching personnel as an aid in explaining and illustrating particular topics of photogrammetry to the students [Fluehler et al., 2005]. 
Shape Capture is image-based modeling software released by ShapeQuest. Itfocuses on target and feature extraction, target and feature space measurement, camera calibration, stereo matching and 3D modeling.

PhotoModeler is digital photogrammetric software used to extract 3D geometrical data and to reconstitute 3D models from 2D images. It is based on the measurement of the homologous points on a block of images carried out with one or more cameras. This software supports digital amateur cameras and many solutions are proposed to realize the interior orientation for both analogue and digital format. The software has an algorithm of a free network adjustment, which can be used in the event of the absence of the control data. In PhotoModeler we can export text files (which contain the orientation parameters and the pixel co-ordinates of measured points), DXF files, VRML files and other formats[Pierre \& Omar, 2000].

Dimension software is designed to be used to measure dimensions and build 3D models of photographed objects. It can use the scanned photos, digital photos, scanned illustrations, digitized video frames, etc. With this software, mono and multiple image modeling are possible. In fact, it is equipped with a special measurement toolbox which allows the determination of 3D information from single images. The accuracy of the resulting model depends on the image quality, the image scale and the number of available images. Only DXF format can be exported. It allows the communication between Dimension software package and CAD/CAM systems. We can notice that this software does not allow texture contribution.

Photo 3D is a software that allows creating 3D models with textures from photos. Photo3D isdeveloped to create these models from single and multiple images. The correction of lens distortions ispossible and the created models can be examined in a preview mode. Relations between lines suchas parallelism and orthogonality (geometric constraints) are used to determine the spatial relationbetween the camera and the object. This model, named the glass-painting model (which istheoretically equivalent to pinhole camera model), is used to calculate automatically the eye positionand the direction of $\mathrm{x}$, $\mathrm{y}$, z-axis of real-world co-ordinate relative to image rectangle.

CanomaMeta Creations, 1999 is software intended for creating photorealistic 3D models from illustrations (historical materials, artwork, hand drawn sketches, etc.), scanned or 
digital photographs. Based on image-assisted technique, it enables to attach 3D wireframe primitives and to render a 3D image by wrapping the 2D surfaces around these primitives. All of the 17 built-in wireframe templates are simple geometric such as planes, rectangles and polygons or basic architectural elements like arches and tables. The textures may be taken directly from the original photos. We can also mirror textures to fill in the invisible sides of object. Canoma uses many image formats such as: BMP, GIF and JPG and allows exporting 2D (BMP, PSD, TIFF, etc) and 3D files (DXF, VRML, etc). Three formats of animation are available: QuickTime, Sequential BMP (PC) and Sequential PICT (Mac).

3D Builder Pro is a window-based application developed by 3D Construction Company. It covers a wide range of custom modeling situation and enables the user to work with one, two or more photos and to take textures directly from the original photos. 3D Builder is also equipped by a 3D Preview window, which shows an interactive, rendered and textured model. With this software, we can use different camera types and different image formats including Photo CD, TIFF, JPEG, BMP and Sun raster. The 3D generated model can be exported under many formats: DXF, VRML, and 3D Studio. It is also compatible with most other rendering packages.

E-FOTO is recent developed software designed as a digital photogrammetric softcopy kit covering most basic phases of a standard photogrammetric workflow. Although the aspect of 'self-teaching' is not the main issue in the software presented in our contribution, a similarity with E-FOTO lies in its 'freedom of software' aspect, namely its accessibility to users who might distribute the software or study its code and even possibly modify it.

\section{3- Research Objective:}

The main objective of this research work is to emphasize the importance of having free photogrammetric software package. This package can be used in both academic and commercial projects. The benefit of having this software package can be touched when one need to apply a specific research task not found in the existing commercial software. More extended reason can be appears when the researcher want to improve or modify existing algorithm in the ready made software. ADPS in this research work presents its 
basic stage (measurement, space resection, space intersection and planning of flight missions).

\section{4- Methodology:}

\section{4-1- SW Development Life Cycle Development:}

In order to achieve the research objective SW development follows the water fall software development model as shown in Fig. 1.

Initiation \& Feasibility:A review of current systems was performed. Then it is followed by feasibility study on the current systems to see if making a new system is feasible. By the end of the initiation and feasibility study a project plan for the future stages of the cycle is determined.

Investigation: A detailed investigation of the users needs is performed. From this investigation the authoridentified the inputs, processes, outputs, and data flows necessary for SW development.

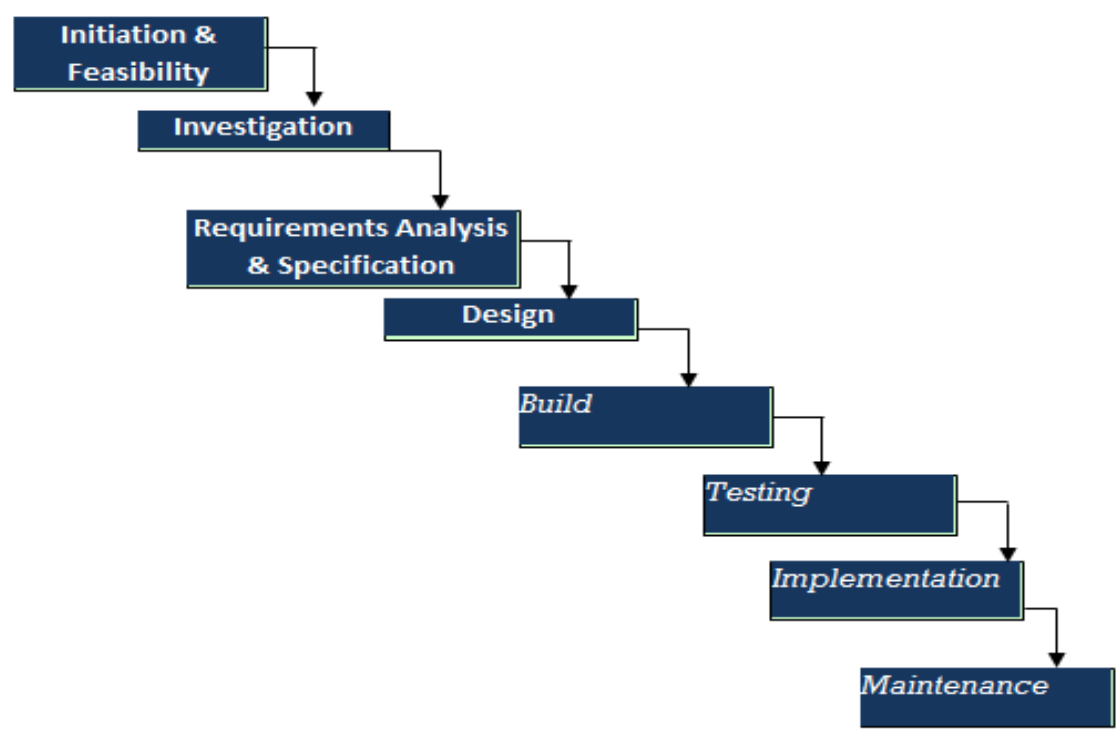

Fig.1:SW development life cycle using water fall model [Serwa \&Semary, 2016].

Requirement, analysis, and specification:This step involves the collection of all the information, and the development of a plan for the creation of aSW. At this point the ADPS was selected for the name of the SW. 
Design: This stage identifies how the ADPS system will look and run in details such as the interface design and coding.

Build: The developer use the design stage plan and converts the acquired information into computer code. Computer programs are written for every part of the system, normally done as series of modules in the project.

Testing: In this stage,the SW is tested to ensure that it performs the functions identified during the design stage. Data are used to insure the reliability of the SW.

Implementation:This step insures that there are very few or no problems for system users. When the system is being installed the users are trained in how to use the new system.

Maintenance: This is the final step in the cycle. Users of the developed system can report bugs in the SW they discover. Some improvements can be applied to the system or the cycle can be returned to the first stage according to the conclusions and reports [Serwa \&Semary, 2016].

\section{4-2- Application Design:}

In order to achieve the research objective a block diagram must be presented to facilitate understanding the system. Fig.2 shows the block diagram for the developed system of ADPS. The pseudo code can be as follow:

Step1: Input project information (name, description and administrator).

Step2: Input photo information (mostly binary bits).

Step3: Input spatial data (GPS coordinates or any reference system).

Step4: Model selection (select the desired algorithms or mathematical model).

Step5: Input initialization parameters (mostly interior and exterior orientation initial values.).

Step6: Carry out space resection initially.

Step7: Refine the space resection by excluding max residual control points (if applicable) and evaluate the selected model.

Step8: re-carry out space resection.

Step9: Carry out space intersection. 
Step10: Product processing (mapping, modeling, contouring and finishing.

Step11: Output of the final product (maps, measured photographs, contour maps....etc.).

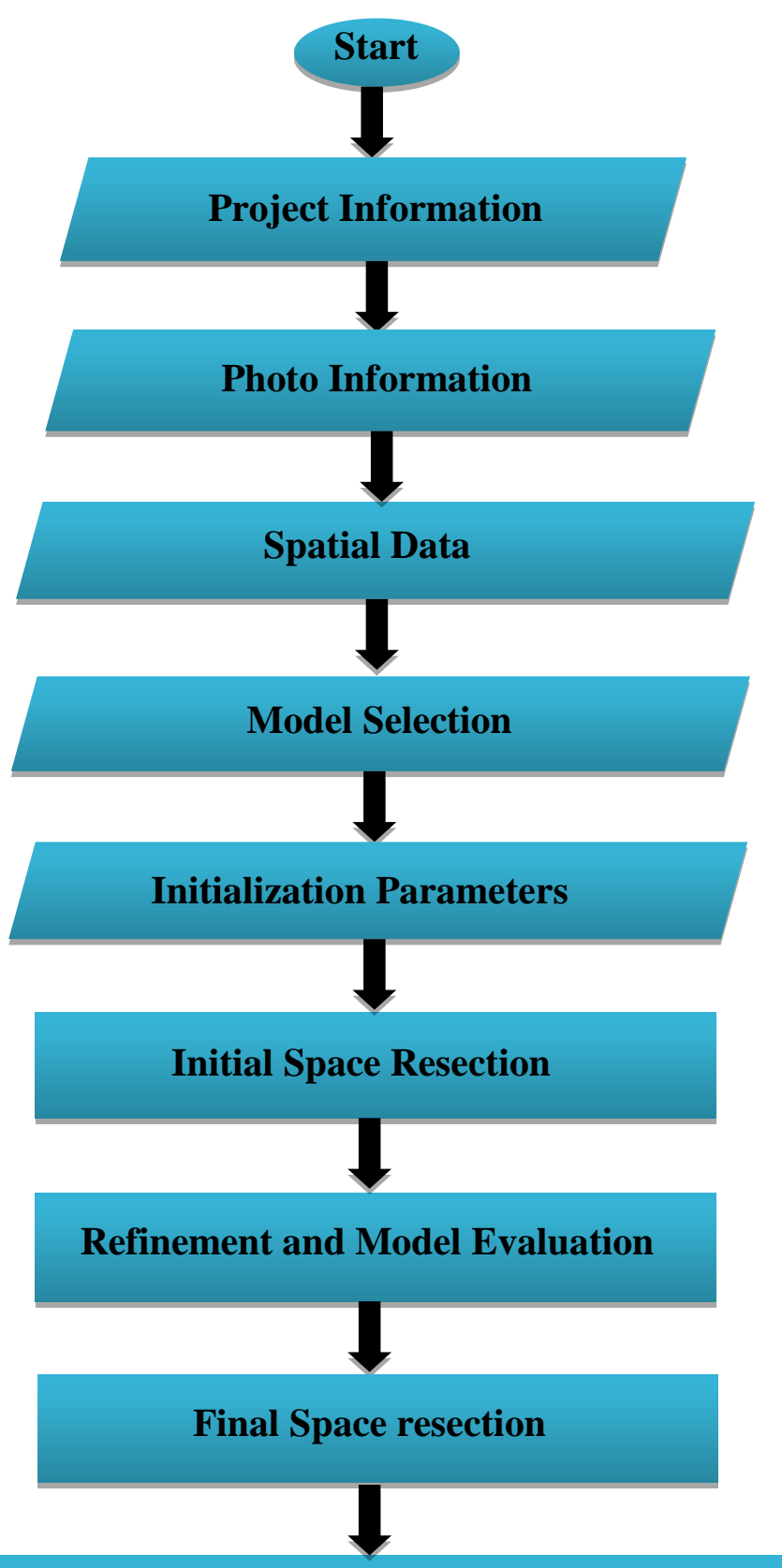

Space Intersection

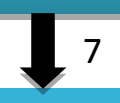




\section{4-3- ADPS Modules:}

Fig.2: System Block Diagram.

ADPS SW was developed using VB6 programming language. It has the following forms:

1- Starting form: Contains author affiliation and institution as shown in Fig. 3.

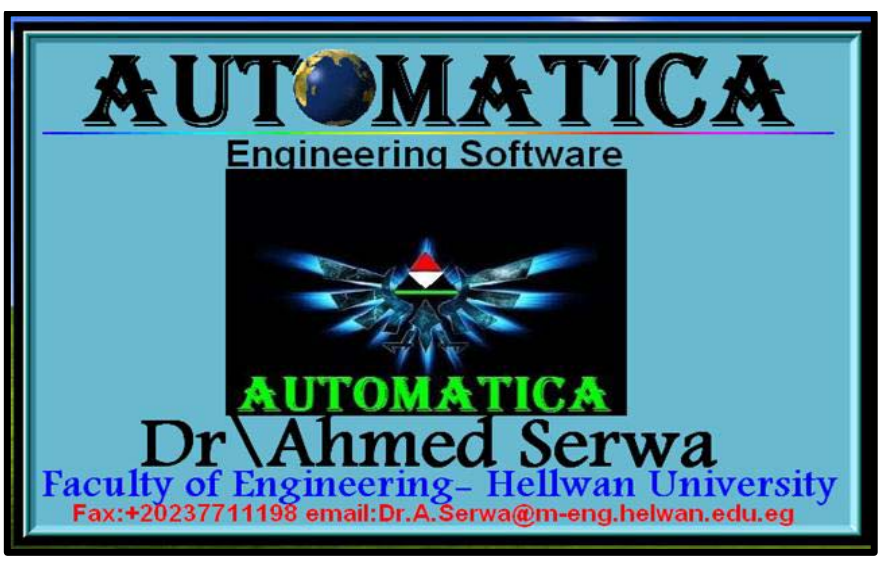

Fig. 3: Starting Form.

2- Identification form: Identifies the SW name and purpose as shown in Fig. 4. It is designed to indicate the general purpose of the developed system.

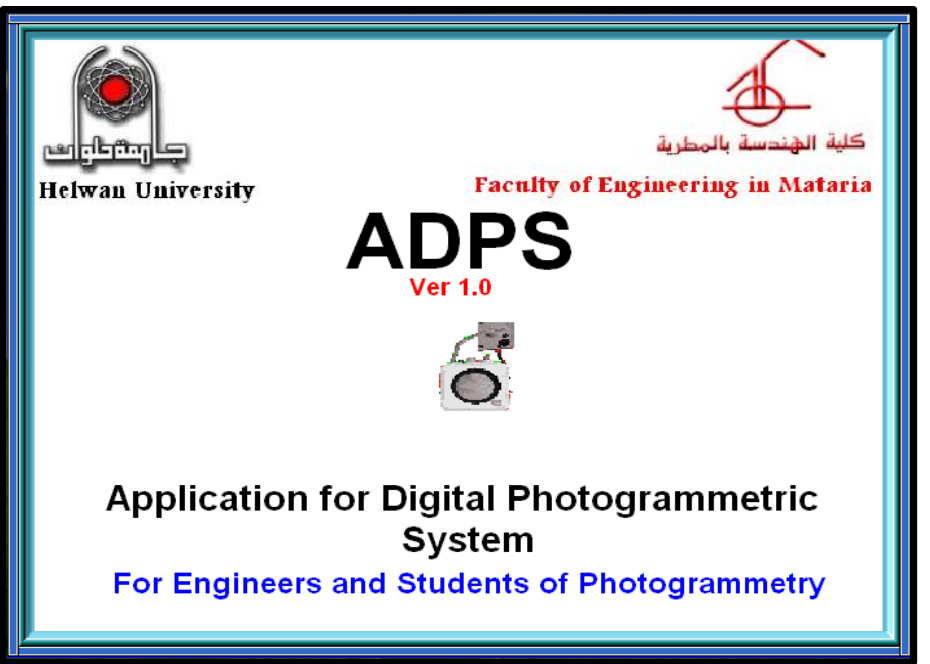


Fig. 4: Identification Form.

3- Main form:It contains the control menus Project, Input, Output, Measure, Processing, View, and shown $5,6,7$

\begin{tabular}{|c|c|}
\hline \multicolumn{2}{|l|}{$\square$ ADPS } \\
\hline \multicolumn{2}{|c|}{ Project Input Output } \\
\hline \multicolumn{2}{|l|}{ New } \\
\hline Open... & Ctrl+o \\
\hline Close & $\mathrm{Ctrl}+\mathrm{C}$ \\
\hline Planning & $\mathrm{Ctrl}+\mathrm{M}$ \\
\hline Save & Ctrl+s \\
\hline \multicolumn{2}{|l|}{ Save As... } \\
\hline \multicolumn{2}{|l|}{ Save All } \\
\hline \multicolumn{2}{|l|}{ Properties } \\
\hline \multicolumn{2}{|l|}{ Page Setup... } \\
\hline \multicolumn{2}{|l|}{ Print Preview } \\
\hline \multicolumn{2}{|l|}{ Print... } \\
\hline Exit & \\
\hline
\end{tabular}

Fig. 5: form Project

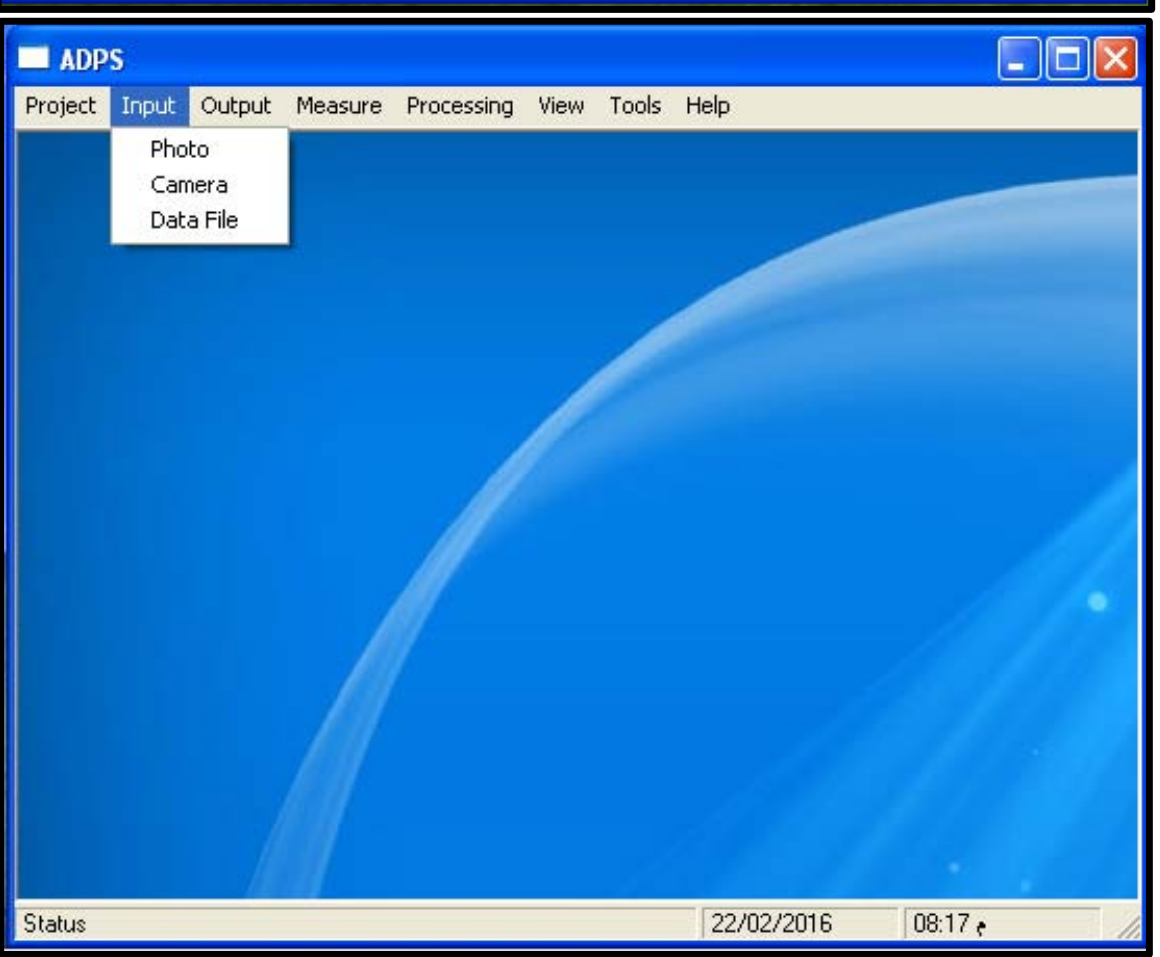

Main

with menu. 
Fig. 6: Main form with Input menu.

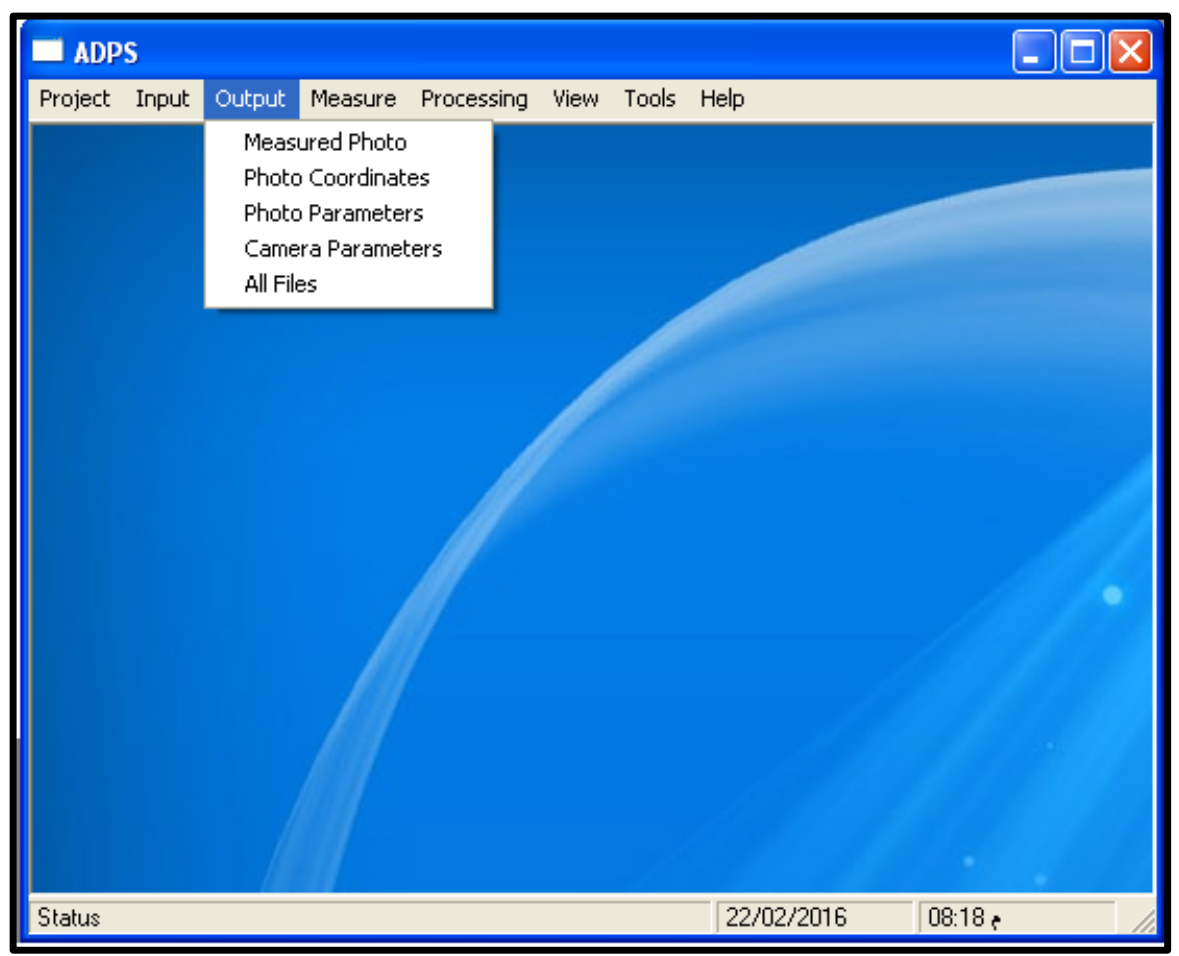

Fig. 7: Main form with Output menu. 


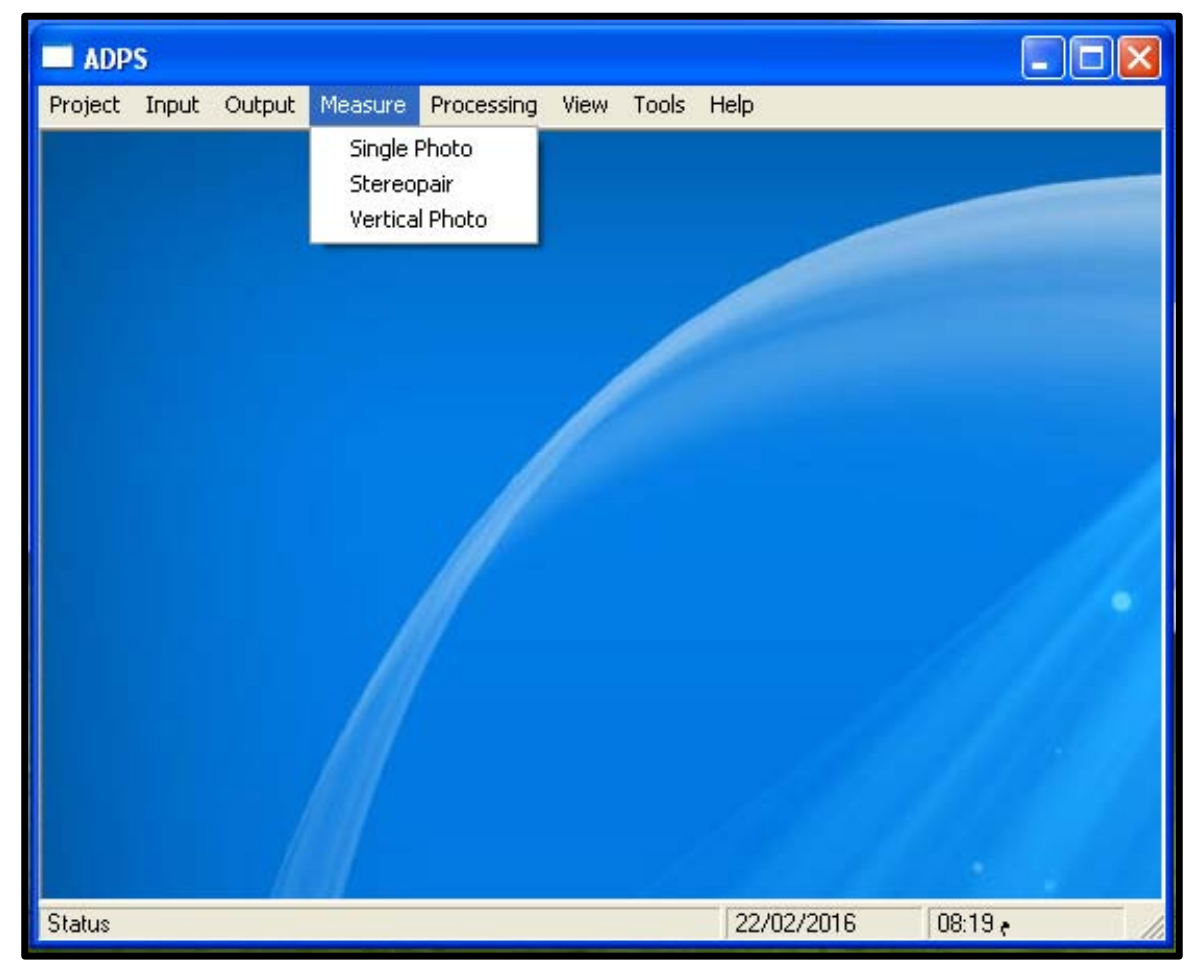

Fig. 8: Main form with Measure menu.

4- New Project form: This is the first step in the developed system. Some basic information must be provided such as project name, administrator name and project description as shown in Fig. 9.

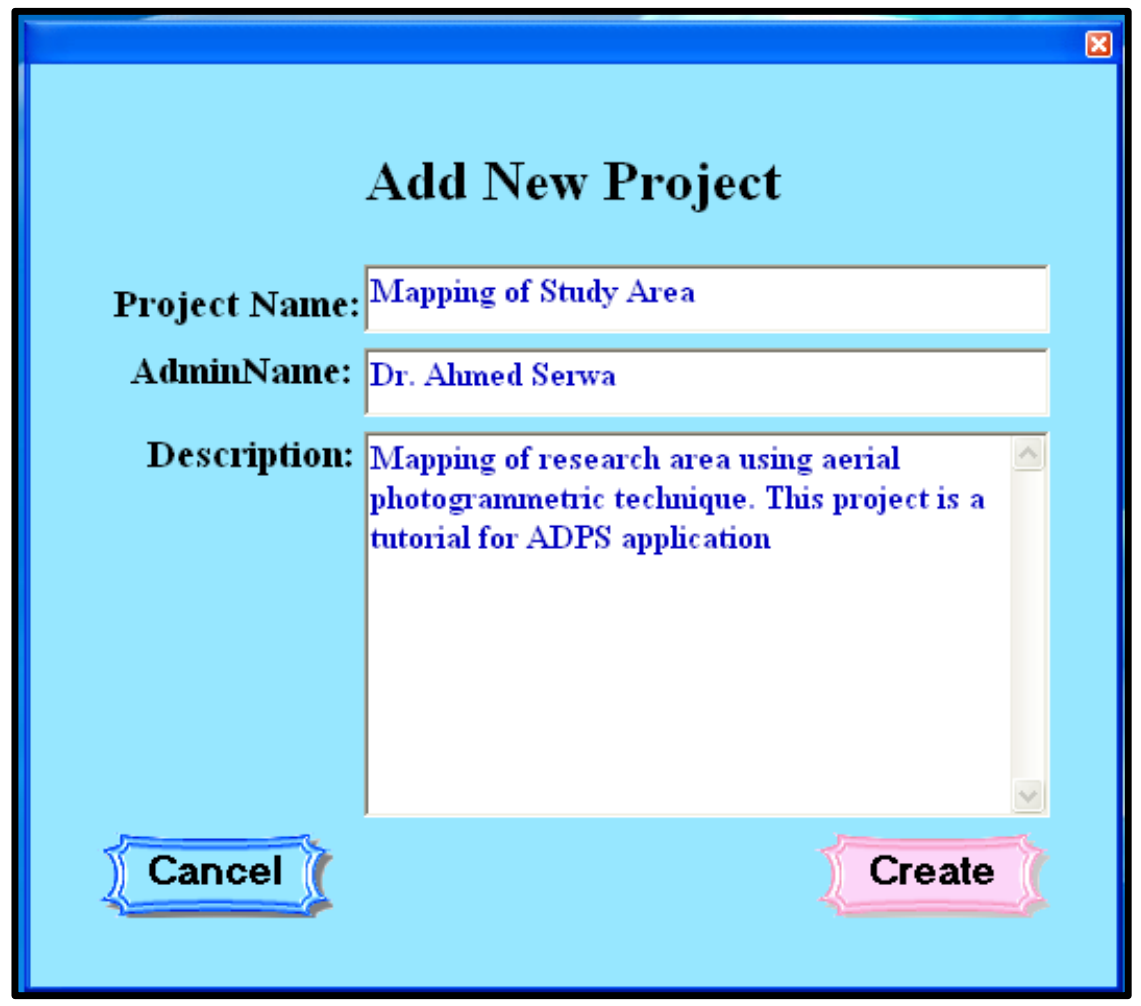


Fig. 9: Compass form.

5- Measure Single Photo form:This form can be used to input single photo coordinates interactively as shown in Fig. 10. Some good features are available such as zooming, moving and tabulating the data. This form can be accessed after creating the project followed by entering measure menu and finally pressing single photo sub menu. The supported image formats are the same as the operating system (mostly Win 7). Meta data is not supported in this form but may be it will be covered in the next versions.

6- Stereopair form:This form can be used to input Stereopair photo coordinates interactively as shown in Fig. 11. Most of the features in single photo form are available in this form. Another good feature is available it is moving both photos together. The ground coordinate of selected points can entered in data file. This form can be accessed after creating the project followed by entering measure menu and finally pressing

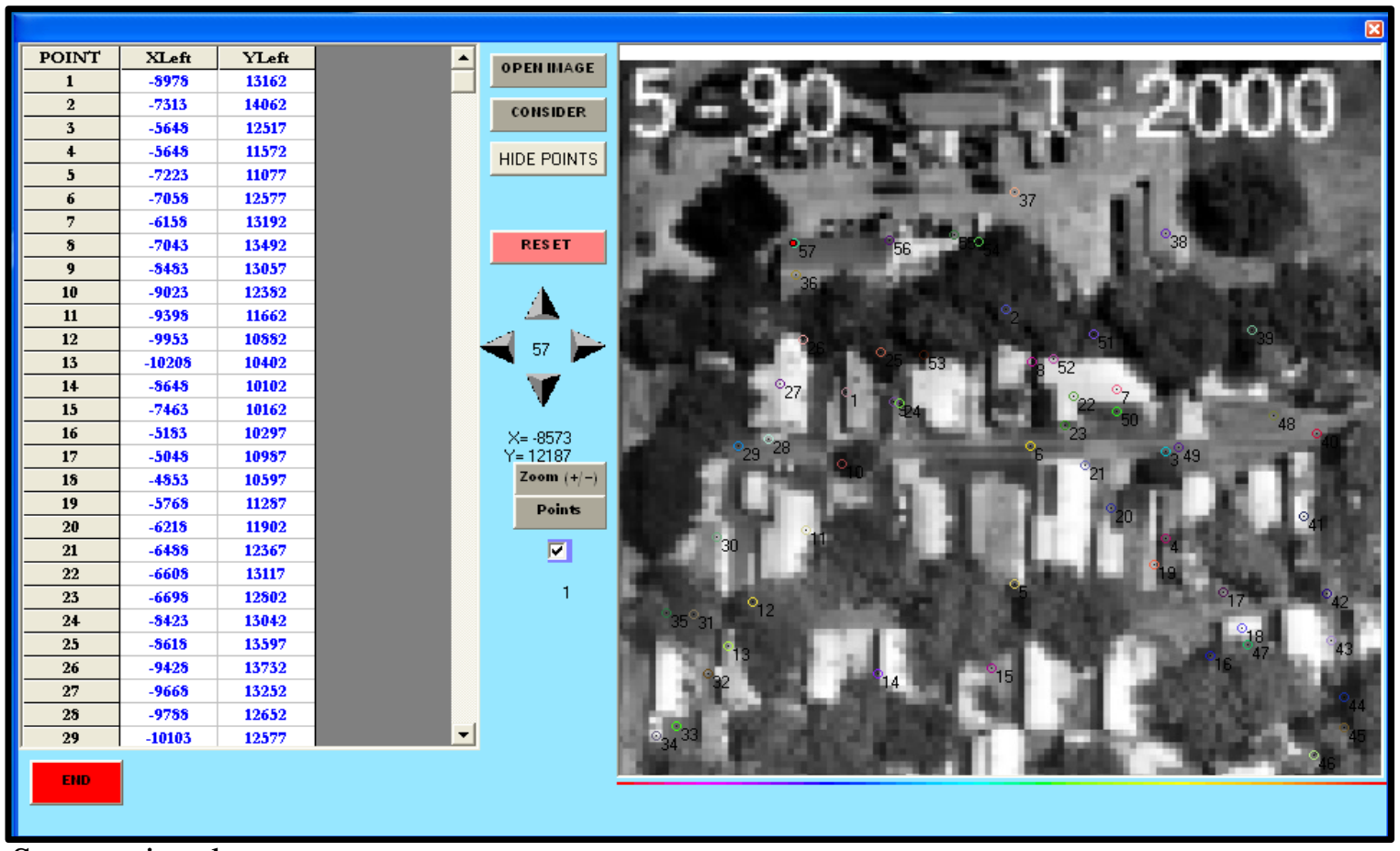

Stereopair sub menu.

Fig. 10:Single Photo form. 


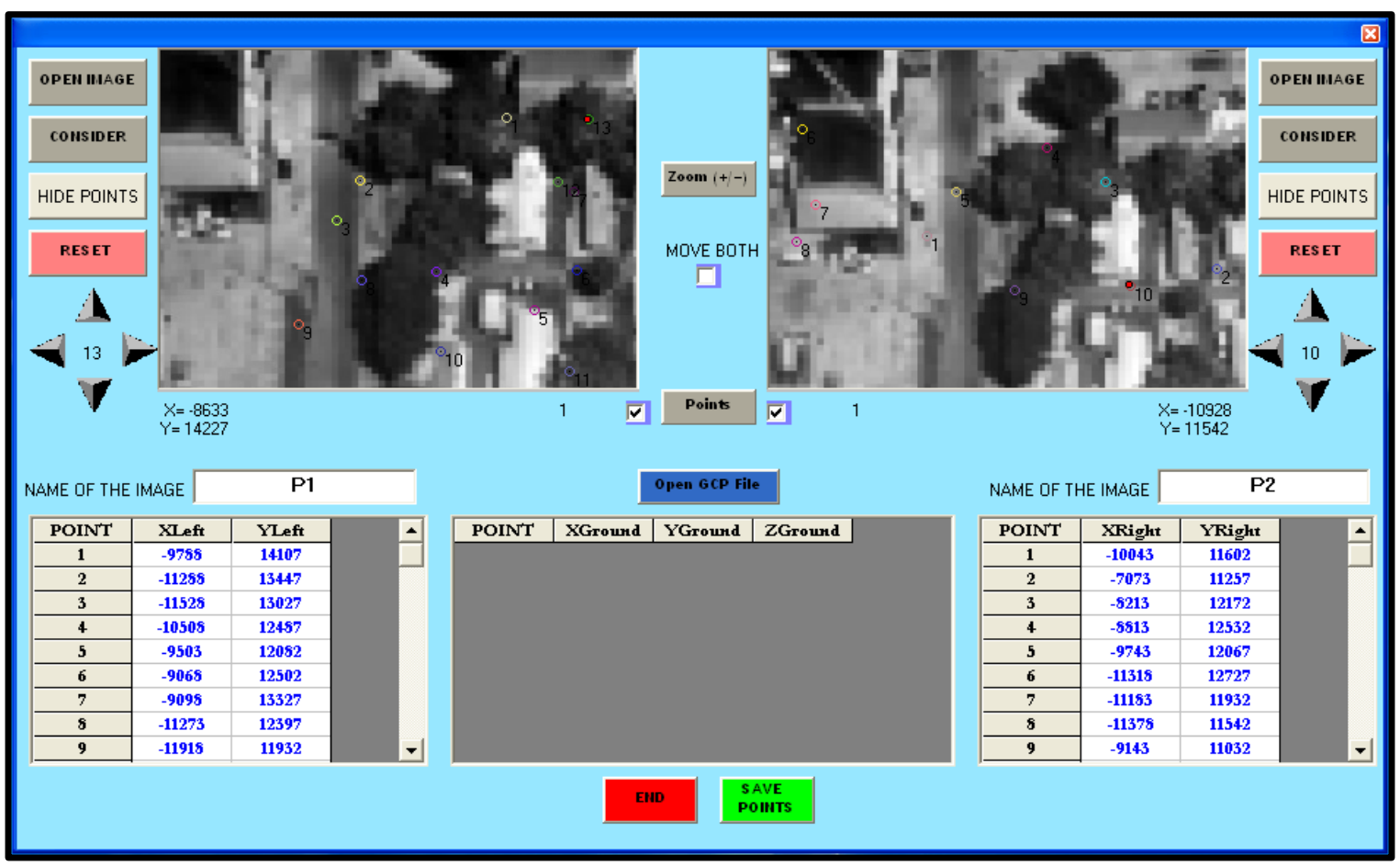

Fig. 11:Stereopair form.

7- Flight planning form:This form is a part of 3A3P project and it is available in this package as demo version due to the copy right transfer restriction. 


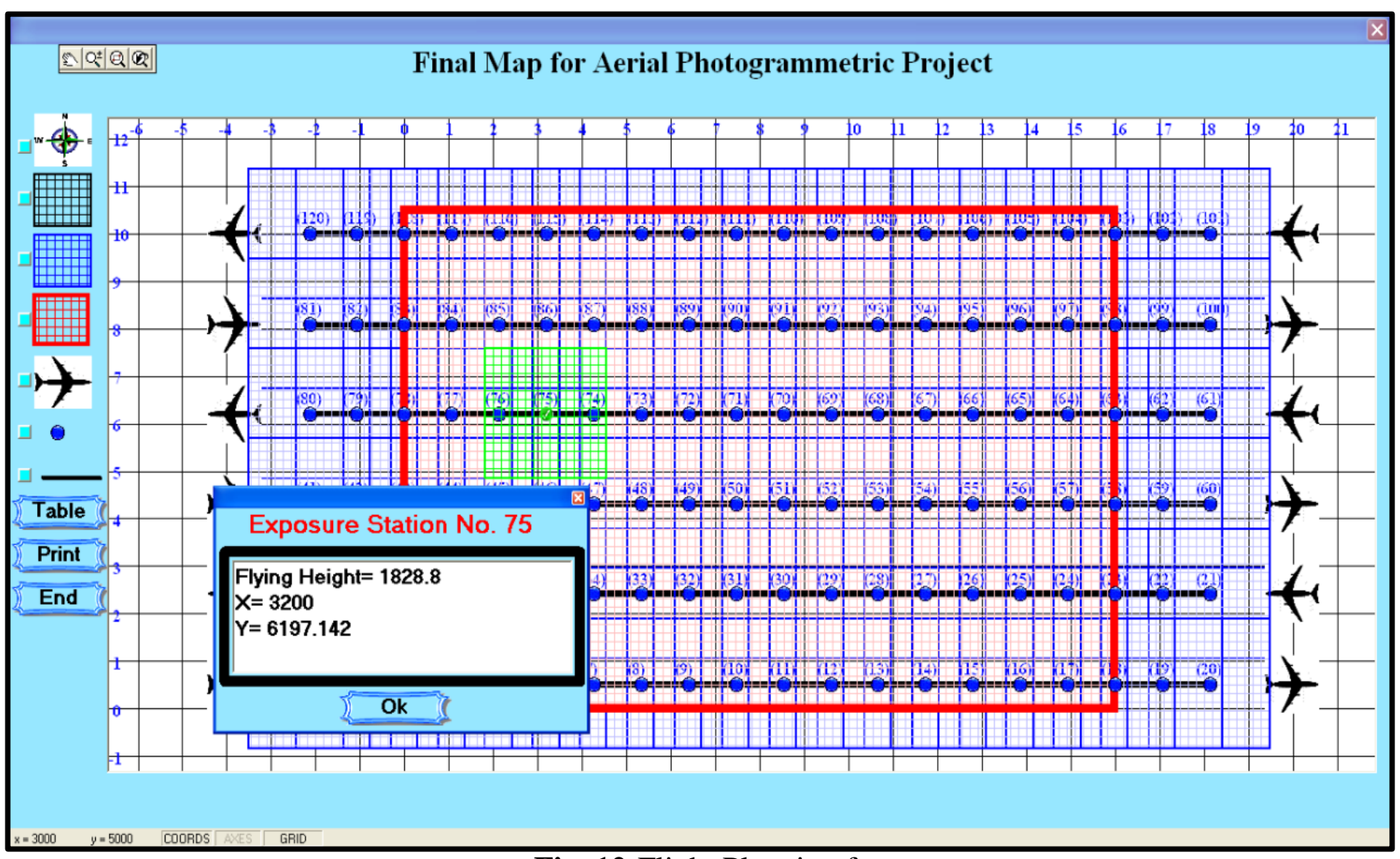

Fig. 12:Flight Planning form.

\section{5- Conclusion:}

It is obvious that the developed system is a photogrammetric educational SW package handling basic tasks (in this version). This paper is posing a suggested educational SW package in its basic level. The developed SW is a self developed so it is free. One can request the free SW from the author for research cooperation. Some additional features must be provided such as supporting for Meta data (.eux data files). The system is fully Egyptian creation without any outboard support (neither scientific nor commercial support).

\section{References:}

- Sedek M., Serwa A., 2016, "Development of new system for detection of bridges construction defects using terrestrial laser remote sensing technology", Egypt. J. Remote Sensing Space Sci. (2016),http://dx.doi.org/10.1016/j.ejrs.2015.12.005.

- Serwa A. Serwa, Semarry H., 2016, "Development of Soft Computational Simulator for Traversing”, Surveying and Land Information System (SaLIS) Journal, ACSM.Vol. (75), Issue (1), Sheridan Press. (Under Publish) 
- Fluehler, M., Niederoest, J., Akca, D., 2005. Development of an educational software system for the digital monoplotting.International Archives of Photogrammetry, Remote Sensing \& Spatial Information Sciences, 36(6W30) [on CD-ROM].

- Förstner W., 2009. Wolfgang Förstner, University of BonnComputer Vision and RemoteSensing - Lessons Learned. InAct of 52th photogrammetric week, Stuttgart, 2009.,pp 241-249.3dsee 2009, http://3dsee.net/

- Kasser M. and Egels Y., 2002. Digital photogrammetry.Taylor \& Francis, London.

- Pierre GRUSSENMEYER \& Omar AL KHALIL, A COMPARISON OF PHOTOGRAMMETRY SOFTWARE PACKAGESFOR THE DOCUMENTATION OF BUILDINGSENSAIS-LERGEC, Photogrammetry and Geomatics GroupPolytechnicum of Strasbourg, France, TheMediterranean Surveyor in the New MillenniumSeminar organized by the International Federation of Surveyors and the Land Surveyors Society of Malta18-21 September 2000 - MALTA 